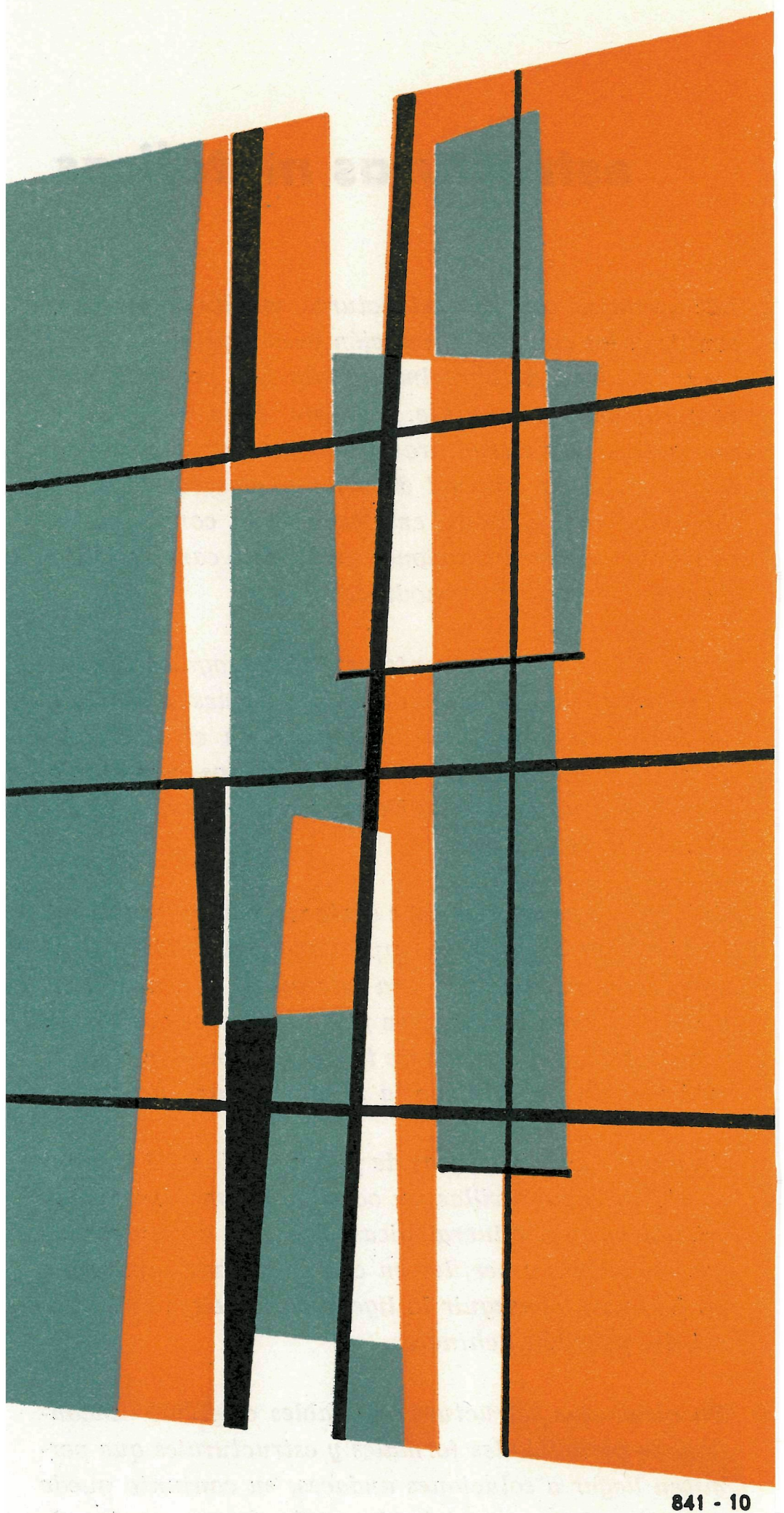

\title{
pabellón Schindler
}

A. BOYER, arqultectoE.T.H. 


\section{estructuras metálicas}

Las ventajas que las estructuras metálicas ofrecen, son de todos conocidas: relación peso-resistencia reducida; facilidad de empalmes, uniones y corte de piezas; rapidez de montaje, etc., etc. Pero hasta hace pocos años las estructuras formadas por barras rectas, en reticula espacial de vigas $y$ soportes de alma llena, era casi la única empleada en la construcción, prestando a sus edificaciones un aspecto caracteristico de rígida y uniforme modulación.

En la actualidad, conjuntamente al progreso experimentado en los métodos de enlace y puesta en obra, se desarrolla un cambio conceptual en el desarrollo de nuevas estructuras, buscando nuevos campos de aplicación basados en la ligereza estructural y facilidad constructiva.

Entre estas novedades cabe destacar, con personalidad fuertemente acusada, el empleo de las estructuras colgantes, cuyos principios son totalmente distintos $y$ en las que la pieza rígida se ve favorablemente sustituida por el cable, cuya forma de trabajo, a tracción simple, está más de acuerdo con la naturaleza del metal.

En unas-las estructuras de piezas rigidas-el ingenio puede hacer maravillas, en ocasiones, semejantes a las cristalizaciones mineralógicas, llegando a emplear vigas en celosia y perfiles en chapa delgada laminados en frío para conseguir la ligereza y esbeltez estructural del pabellón Schindler.

En otras-las estructuras de cables colgados-encontramos posibilidades formales y estructurales que permiten llegar a soluciones audaces; su conjunto puede recordar al de una tela de araña, cuyos puntos de rocio iluminados por el sol naciente, recuerdan los puntos de luz de ellos colgados; tal es el efecto que ofrecen las sencillas y originales lámparas colgadas del hall de operaciones del Palacio de la Bolsa de Turín. 


\section{construcción}

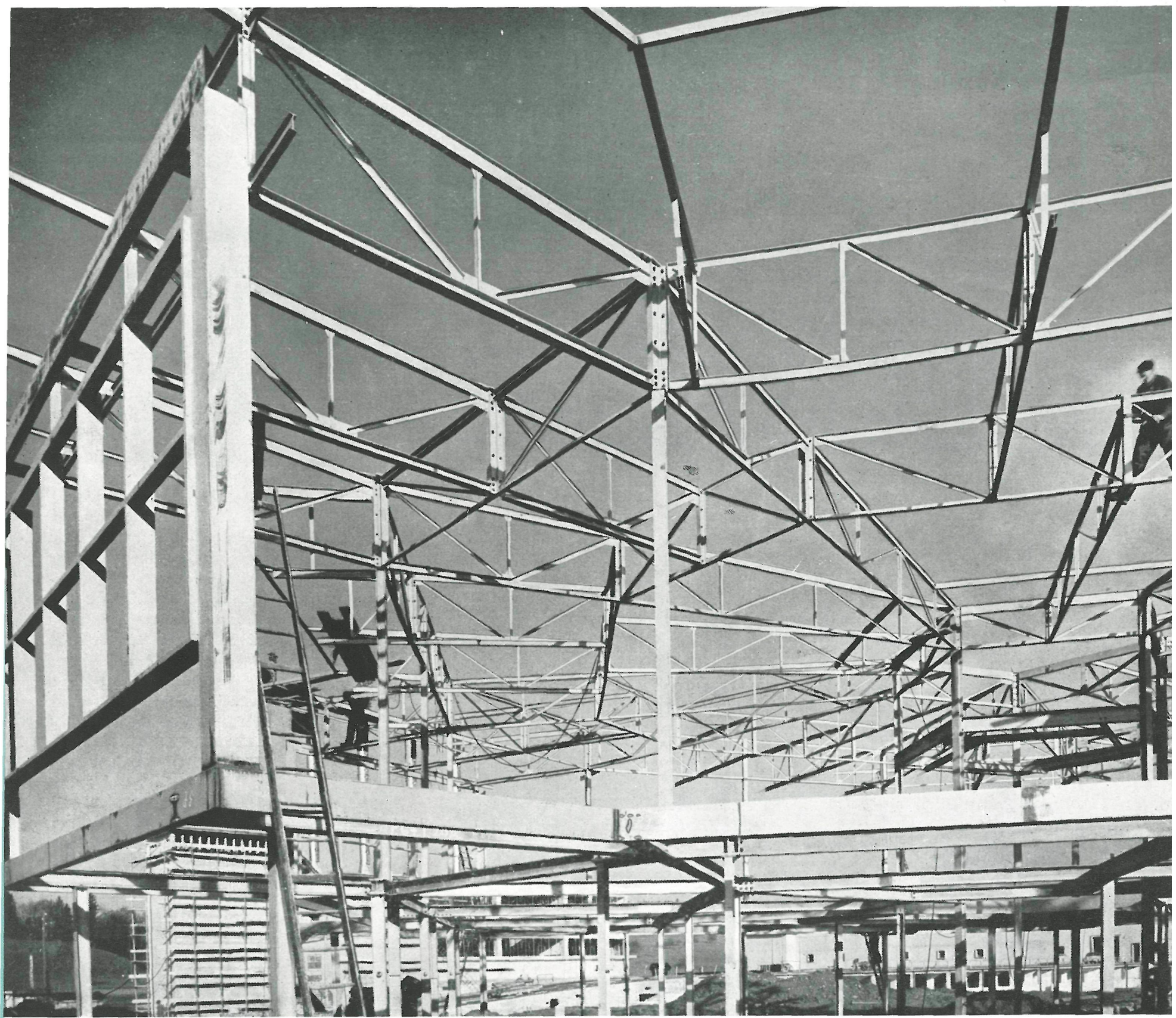

La empresa suiza "Aufzüge- und Elektromotorenfabrik Schindler \& Co AG" llevó a cabo una serie de construcciones para sus empleados, iniciándolas con la construcción de una cantina en un pabellón, desde cuyo comedor se domina el conjunto de la fábrica y las zonas arboladas cercanas.

El plazo muy breve de construcción obligó a proyectar una estructura resistente metálica, resuelta con originalidad, con aspecto de tela de araña por su ligereza y esquema. El trazado de éste, en líneas generales, está formado por tres pentágonos, inscritos en otras tantas circunferencias concéntricas, de radio de 3,9 y $16 \mathrm{~m}$, las cuales constituyen los anillos de atado. 


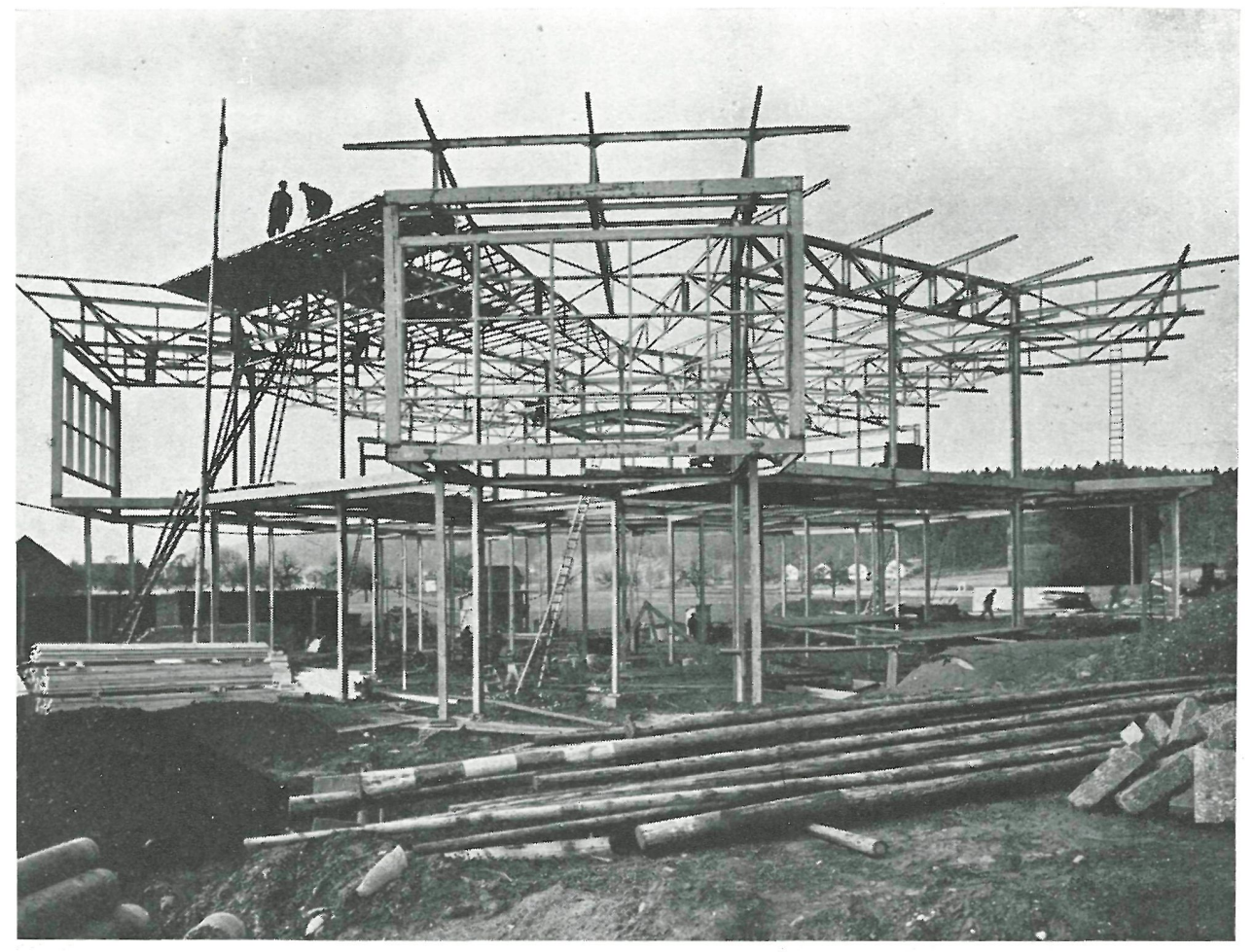

\section{$p$ lanta}

estructura

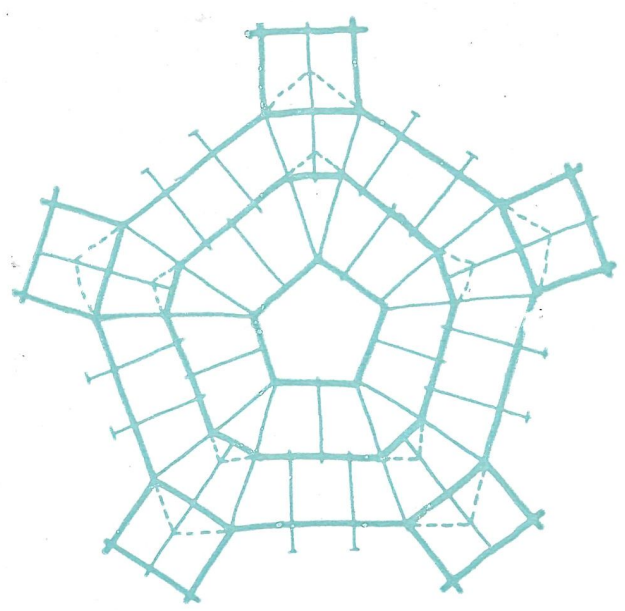

Los vértices de los dos exteriores están truncados.

La anterior disposición pentagonal ha dado al entramado su ligereza;

y aunque con ella el número de barras es importante, las dimensiones de éstas son siempre moderadas. Las vigas transversales trianguladas se realizaron con perfiles doble $\mathrm{T}$ y $\mathrm{T}$ de pequeña sección. En las vigas las piezas van soldadas.

En los nudos de la estructura se empleó el sistema de tornillos. En el anillo de borde se ha utilizado un perfil especial, realizado en chapa de acero doblada y soldada a tope

a las cabezas de las vigas. Los pies derechos son perfiles doble $\mathrm{T}$, presentando una curiosa disposición en planta baja, ya que se rompe su continuidad en el nudo

y el pie derecho se convierte en pilares dobles

atornillados a las vigas a escasa distancia de los nudos.

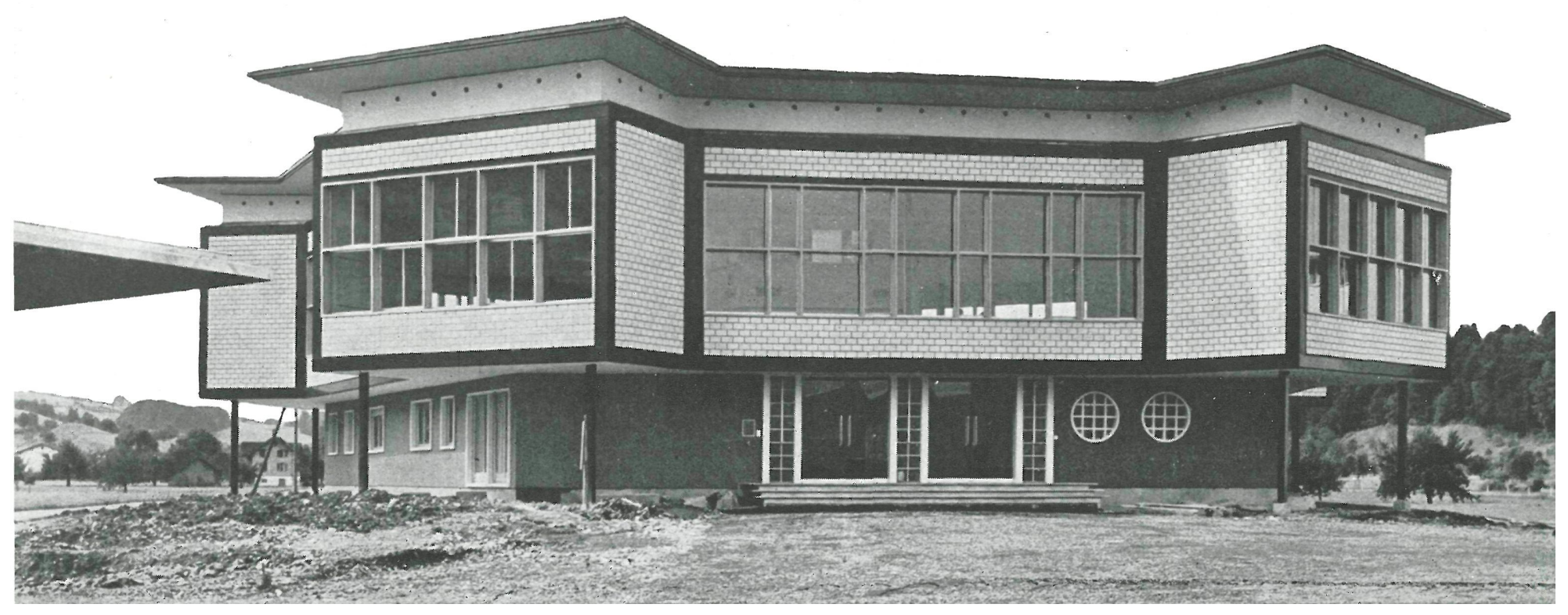




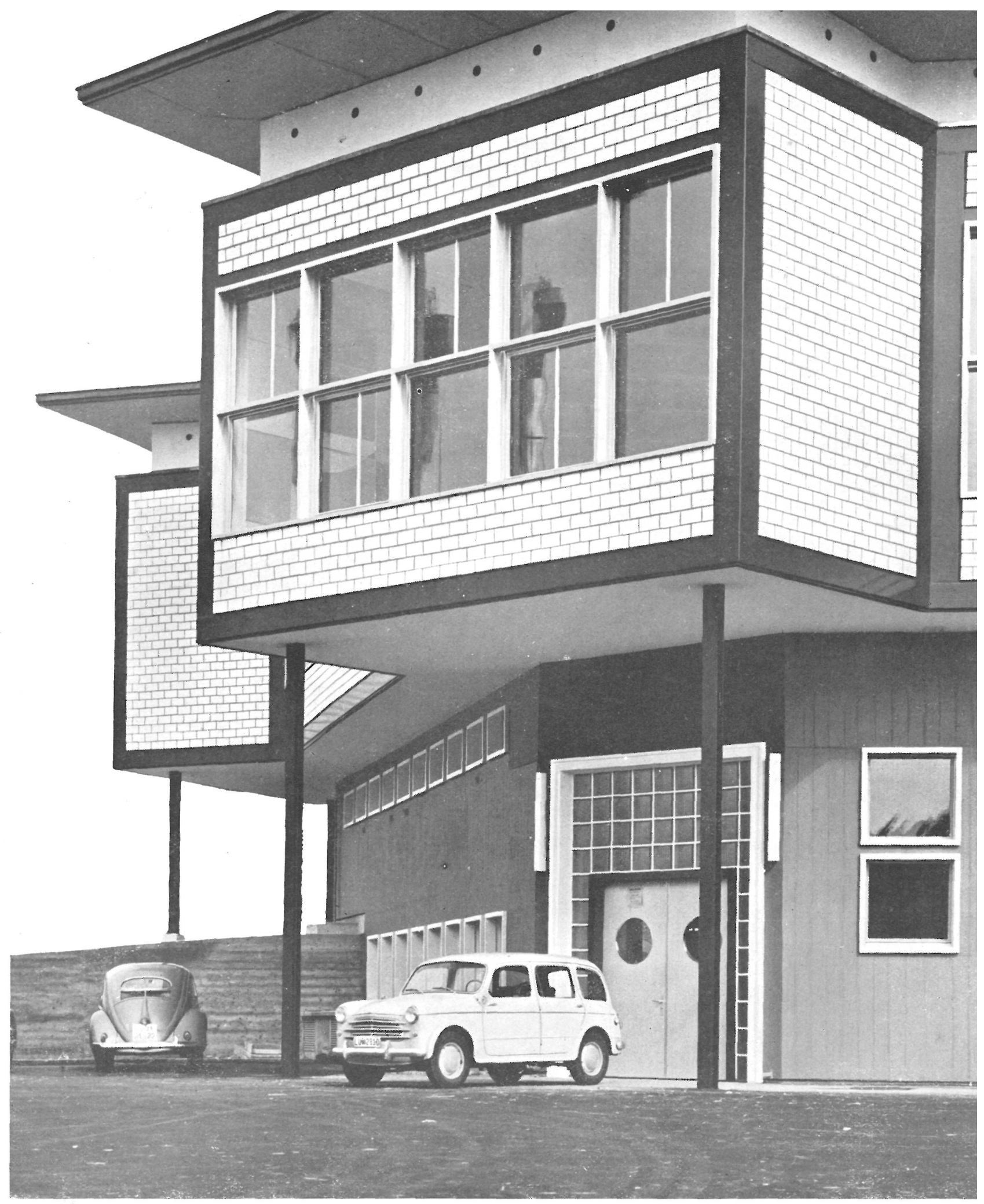

Toda la estructura se montó en diez semanas, y dentro del indudable interés de todo el pabellón, es, junto a las instalaciones especiales, lo más interesante. Todo el edificio posee aire acondicionado; las cocinas están dotadas de ventilación especial. Las instalaciones de éstas son muy completas: cámaras frigoríficas (para bebidas, legumbres, diurna, de baja temperatura para carnes $\left(-8^{\circ} \mathrm{C}\right)$, para pastelería, y de conservación de comidas), tres termos con una capacidad de 6.000 litros, siete autoclaves (de 100 a 400 litros de capacidad), tres sartenes automáticas, un fogón con planchas reversibles para asados y una máquina lavaplatos. 

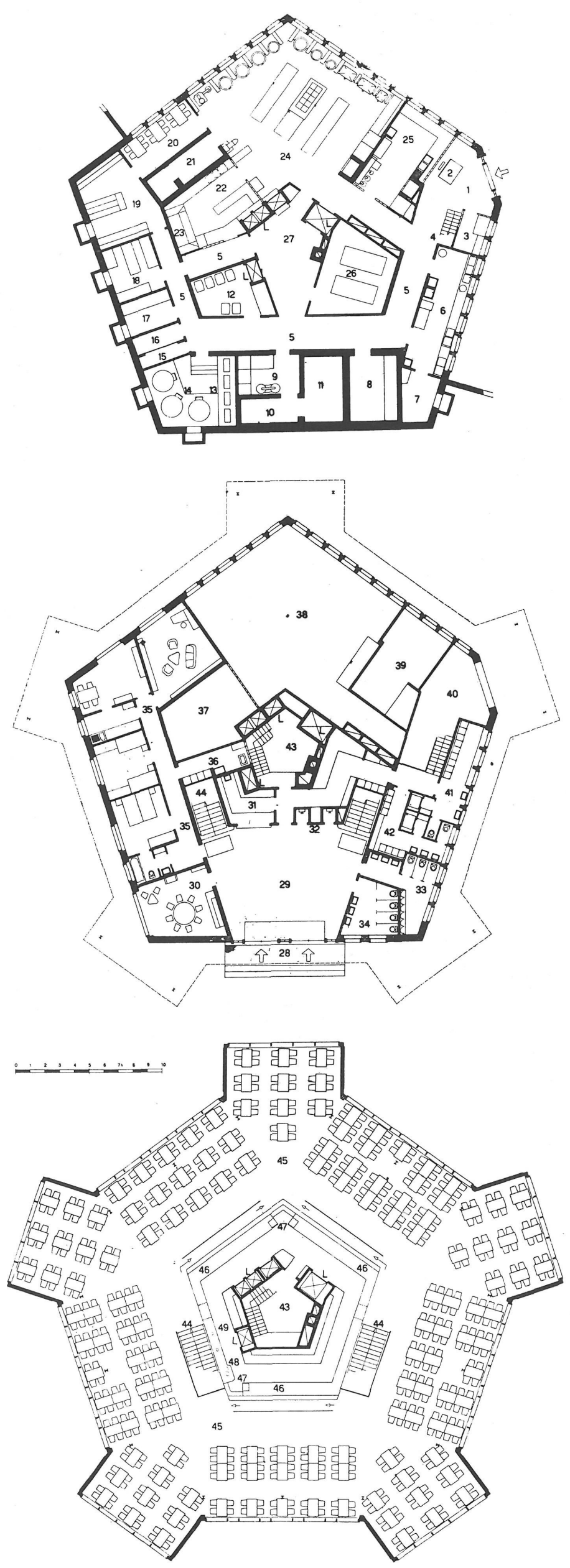

En el comedor, el buffet central tiene $40 \mathrm{~m}$ de longitud, seis armarios calientes y seis refrigerados; la iluminación es fluorescente, y se ha instalado un sistema de avisos por altavoces, tocadiscos y radio.

Las comunicaciones entre la cocina y el comedor están servidas por cinco montacargas.

Utilizarán el comedor unos 2.000 empleados. En el comedor, en un principio se pensó en la existencia de personal de servicio, idea que fué más tarde desechada y se decidió que cada uno de los usuarios se sirviese a sí mismo. Los empleados comerán en tres series, con lo que el comedor podrá tener proporciones más reducidas y agradables. Para organizar el servicio de manera racional se estableció un centro para el reparto de las comidas, desde el cual la distancia no fuese excesiva a cualquier lugar del comedor. Esta disposición y la gran superficie de huecos hace el interior luminoso. Desde el exterior no pueden apreciarse las dimensiones reales de la sala. En su decoración y mobiliario se utilizaron tonos neutros, y el arquitecto reservó diez grandes paneles entre las ventanas para realizar pinturas murales, explicando al realizador Eduardo Renggli sus ideas, consistentes en alegrar con ellos el ambiente del comedor sin que llegasen a ser centro principal de atención. El pintor realizó una decoración abstracta, de colores frescos en tonos suaves-verdes, azules, amarillos, coñac y ceniza-. Los resultados fueron satisfactorios y los empleados de la fábrica disponen de un magnífico servicio en ambiente agradable, en el cual los paneles son un ligero toque de color.

Se entra al pabellón a través de un hall decorado en tonos fríos, y a su lado están situadas las cabinas telefónicas y aseos. En la entreplanta se distribuyen: los vestuarios, aseos para el personal de cocinas y vivienda de los guardas. 


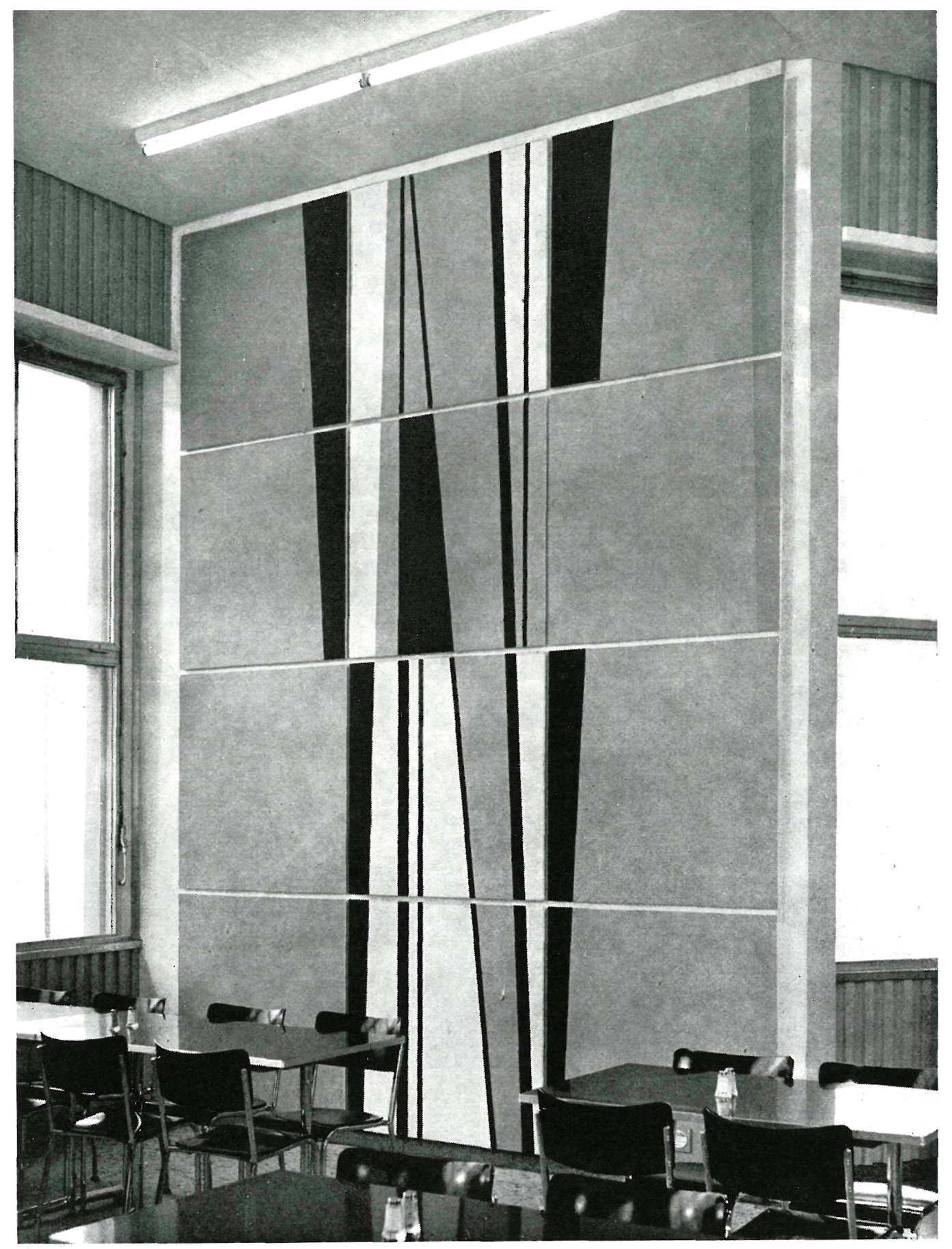

panel 


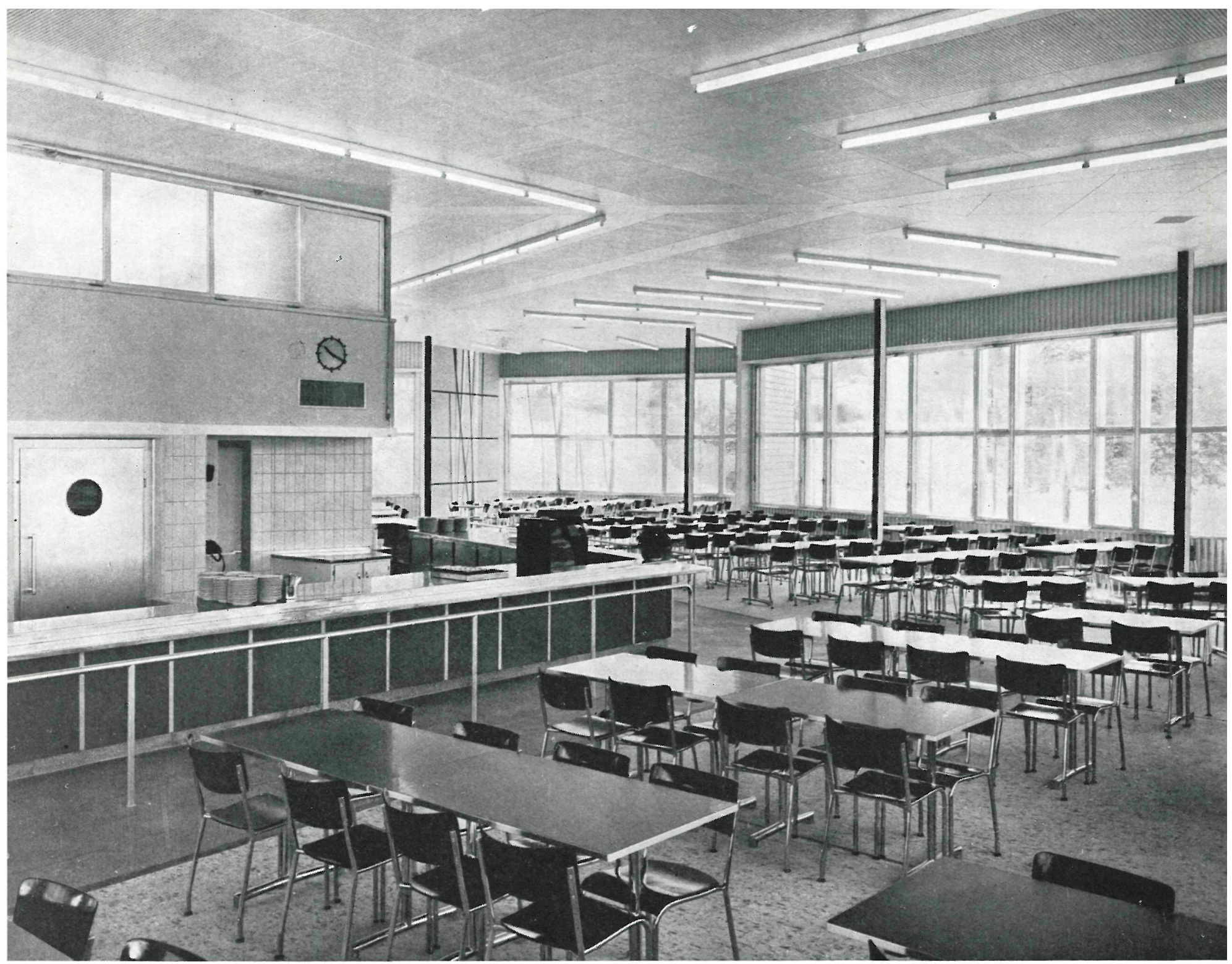

interiores

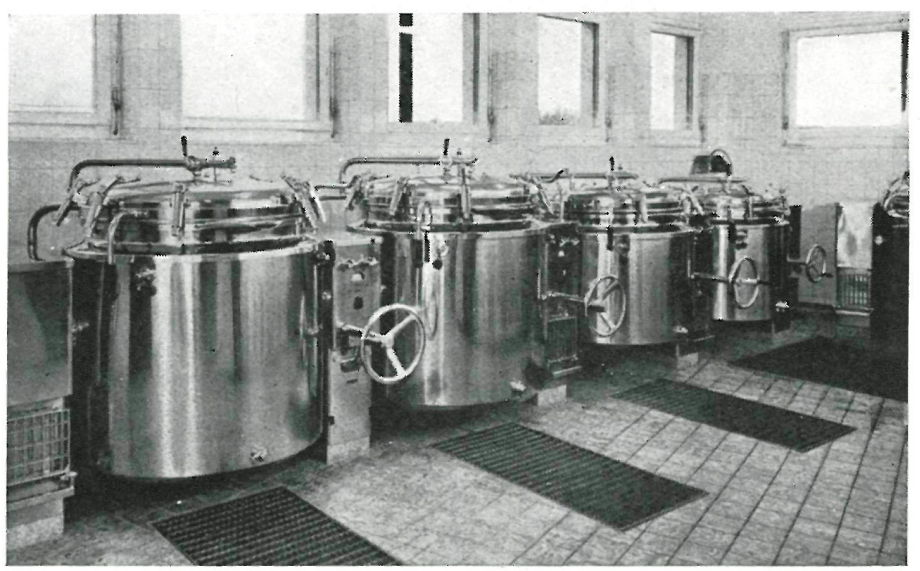

En planta primera: la cocina principal, office, frigoríficas, bodega y despensas, economato, sala de máquinas, calefacción y despacho del jefe de la cantina. La segunda planta alberga la gran sala del comedor.

La construcción armoniza con la ya existentes: tonos terrosos en zócalos y muros exteriores revestidos con plancha de acero coloreadas en azul.

Fotos: O. PFElFER, SWB, LUZERN y LAUBACHER

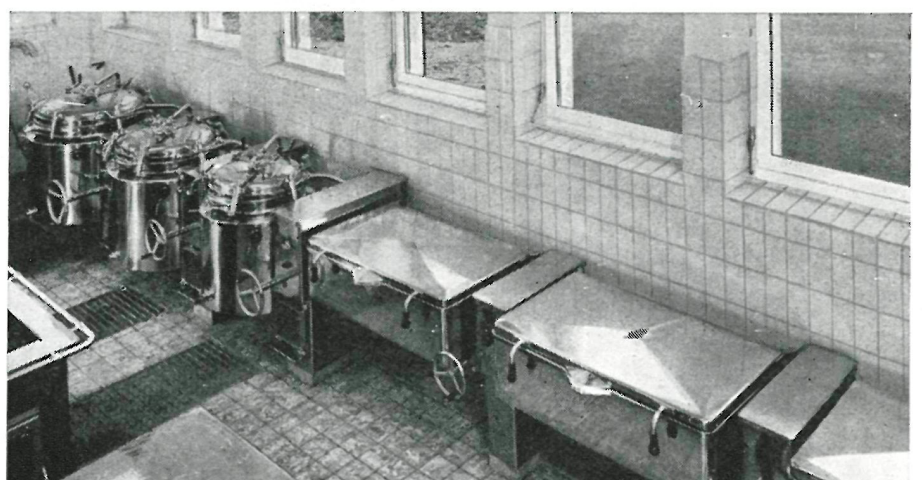

